\title{
Cerebral and cerebellar MRI volumes in Williams syndrome
}

\author{
Ana Osório ${ }^{\mathrm{a}, 1, *}$, José Miguel Soares ${ }^{\mathrm{b}, \mathrm{c}, \mathrm{d}}$, Montse Fernández Prieto ${ }^{\mathrm{e}, \mathrm{f}}$, \\ Cristiana Vasconcelos ${ }^{\mathrm{g}}$, Catarina Fernandes ${ }^{\mathrm{a}}$, Sónia Sousa ${ }^{\mathrm{a}}$, Ángel Carracedo ${ }^{\mathrm{e}, \mathrm{f}}$, \\ Óscar F. Gonçalves ${ }^{\mathrm{a}, \mathrm{h}}$, Adriana Sampaio ${ }^{\mathrm{a}}$ \\ ${ }^{a}$ Neuropsychophysiology Lab, CIPsi, School of Psychology, University of Minho, Campus Gualtar, 4710-057 Braga, Portugal \\ ${ }^{\mathrm{b}}$ Life and Health Sciences Research Institute (ICVS), School of Health Sciences, University of Minho, Minho, Portugal \\ ' ICVS/3B's-PT Government Associated Laboratory, Guimarães, Braga, Portugal \\ d Clinical Academic Center, Braga, Portugal \\ e Biomedical Research Center Network for Rare Diseases (CIBERER), University of Santiago of Compostela, Santiago de Compostela, Spain \\ ${ }^{\mathrm{f}}$ Genetic Molecular Unit, Galician Public Foundation of Genomic Medicine, Galicia, Spain \\ ${ }^{g}$ Department of Neuroradiology, CHP-Hospital de Santo António, Porto, Portugal \\ ${ }^{\mathrm{h}}$ Department of Counseling and Educational Psychology, Bouvé College of Health Sciences, Northeastern University, Boston, USA
}

\section{A R T I C L E I N F O}

\section{Article history:}

Received 10 September 2013

Received in revised form 26 December 2013

Accepted 30 December 2013

Available online 14 February 2014

\section{Keywords:}

Cerebellum

Williams syndrome

MRI

\begin{abstract}
A B S T R A C T
Individuals with Williams syndrome (WS) present a set of cognitive, affective and motor symptoms that resemble those of patients with lesions to the cerebellum. Although there is some evidence for overall structural alterations in this brain region in WS, explorations on cerebellar white matter and cerebellar cortex volumes remain rather neglected. We aimed to compare absolute and relative cerebellar volumes, as well as patterns of white matter to cortex volumes in this brain region, between a group of individuals with WS and a group of healthy controls. T1-weighted magnetic resonance images were acquired in 17 individuals with WS and in 15 typically developing individuals. Our results showed that even though individuals from the clinical group had significantly smaller cerebrums (and cerebellums), cerebellar volumes relative to intracranial volumes were significantly enlarged. In addition, while gray matter was relatively spared and white matter disproportionately reduced in the cerebrum in WS, relative cerebellar cortex and white matter volumes were preserved. These findings support the hypothesis that volume alterations in the cerebellum are associated with the cognitive, affective and motor profiles in WS.
\end{abstract}

(c) 2014 Elsevier Ltd. All rights reserved.

\section{Introduction}

The traditional role of motor coordination attributed to the cerebellum has been challenged by a more complex view, one that encompasses its involvement in cognitive and emotional processing (Stoodley \& Schmahmann, 2010). There is ample evidence that sensorimotor functions rely on the interconnections between the cerebellum and the spinal motor systems (Grodd, Hülsmann, Lotze, Wildgruber, \& Erb, 2001; Nitschke, Kleinschmidt, Wessel, \& Frahm, 1996; Oscarsson, 1965; Schmahmann, 2004). However, fronto-cortico-cerebellar connections are believed to be involved in higher cognitive functions such as language and executive functions (Makris et al., 2005; Schmahmann, 2001), while cerebro-cerebellarlimbic loops are thought to be implicated in emotional regulation and processing (Stoodley \& Schmahmann, 2010).

\footnotetext{
* Corresponding author. Tel.: +351 253604220; fax: +351 253604224.

E-mail addresses: aosorio@psi.uminho.pt, ana.osorio@mackenzie.br (A. Osório).

${ }^{1}$ Current address: Cognitive and Social Neuroscience Lab, Center for Biological and Health Sciences-Mackenzie Presbyterian University, Rua Piauí, 181, 10 andar, 01241-001 São Paulo, SP, BRAZIL.
} 
Indeed, there is mounting functional evidence showing cerebellar activations in language, executive, visual-spatial and affective tasks (Desmond, Gabrieli, \& Glover, 1998; Fink et al., 2000; Harrington et al., 2004; Hofer et al., 2007; Valera, Faraone, Biederman, Poldrack, \& Seidman, 2005; Vingerhoets, De Lange, Vandemaele, Deblaere, \& Achten, 2002; Xiang et al., 2003). Clinical findings also support the notion of a multifold role of the cerebellum, as lesions in different areas of this brain structure lead to distinctive motor, cognitive and affective impairments. In this line, executive, visual spatial and linguistic impairments, along with affect dysregulation (including exacerbated anxiety and hyperspontaneous, disinhibited behavior) have been reported in patients with cerebellar lesions (for a review, see Stoodley \& Schmahmann, 2010). This cluster of symptoms was termed cerebellar cognitive affective syndrome (Schmahmann \& Sherman, 1998) and, depending on the affected cerebellar lobe, has been found to occur independently but also concomitantly with the cerebellar motor syndrome (Schmahmann, MacMore, \& Vangel, 2009).

The overlap and similarities between most of the aforementioned cognitive, affective and motor symptoms of cerebellar damage and the features displayed by individuals with Williams syndrome (WS) is quite striking. WS is a neurodevelopmental disorder with an estimated prevalence of 1 in 7500 live births (Strømme, Bjømstad, \& Ramstad, 2002). It is caused by a submicroscopic deletion on chromosome 7 (region 7 q11.23), including the elastin gene (ELN) (Korenberg et al., 2000). Individuals with this syndrome present distinctive features such as elfin-like face, small stature, hyperacusis, as well as cardiovascular, endocrine and connective tissue abnormalities (Udwin, 2002). Impairments in the cognitive domain include moderate intellectual disability (Howlin, Davies, \& Udwin, 1998; Sampaio et al., 2009), language alterations (e.g., in syntax, morphology, phonology, pragmatics and narrative (Brock, 2007; Gonçalves et al., 2010; KarmiloffSmith, Brown, Grice, \& Paterson, 2003)), compromised executive functioning (Osório et al., 2012; Porter, Coltheart, \& Langdon, 2007; Rhodes, Riby, Park, Fraser, \& Campbell, 2010) and deep visual-spatial difficulties (Atkinson et al., 2003; Bellugi, Korenberg, \& Klima, 2001). Individuals with WS are also well-known for their hypersociability, which manifests itself in the form of uninhibited and indiscriminate social approach behaviors (Capitão et al., 2011; Jones et al., 2000). Concomitantly, various reports underline the high incidence of anxiety disorders, particularly specific phobias and generalized anxiety disorder (Dykens, 2003; Leyfer, Woodruff-Borden, Klein-Tasman, Fricke, \& Mervis, 2006). In addition, WS is characterized by poor motor coordination, odd gait and hypotonia (Chapman, du Plessis, \& Pober, 1996; Trauner, Bellugi, \& Chase, 1989)

Recently, some researchers began to explore structural changes in the cerebellum in WS. Indeed, the cerebellum appears macroscopically enlarged in WS, relative to a small cerebrum (Jones, Hesselink, Duncan, Matsuda, \& Bellugi, 2002; Schmitt, Eliez, Bellugi, \& Reiss, 2001). Reports of overall brain volume reductions in comparison to healthy controls range from around 13\% to 18\% (Reiss et al., 2000; Sampaio et al., 2008), while cerebellar volumes appear to be reduced to a lesser extent (e.g., 7\%, Reiss et al., 2000). However, data so far appear inconsistent-while some authors found evidence for a relative increase in cerebellar volume (Jones et al., 2002; Reiss et al., 2000), others reported volume preservations in this structure using either manual (Jernigan, Bellugi, Sowell, Doherty, \& Hesselink, 1993) or semi-automated segmentation methods (Chiang et al., 2007). Furthermore, patterns of white matter to cortical volumes in the cerebellum seem to be distinct from those observed in the rest of the brain. Reiss et al. (2000) reported a relative sparing of cerebral gray matter along with a disproportionate reduction in white matter in individuals with WS, when compared with a healthy control group. Conversely, no such disproportionate reduction was found in the cerebellum, where white matter volumes were relatively preserved. Apart from this important investigation, no further studies explored white matter-cortex proportions in the cerebellum, so replication is greatly needed.

Our main goal is to compare absolute and relative cerebellar volumes, as well as patterns of white matter to cortex volumes in this brain region, between a group of individuals with WS and a group of healthy controls. By doing so, we aim to provide further insight on how such changes may be involved in their motor, cognitive and affective phenotypes. In accordance with previous findings our hypotheses are as follows: (a) the clinical group will present significantly smaller cerebral volumes than their typically developing counterparts; (b) the clinical group will present a disproportionate reduction in cerebral white matter, but not in gray matter; (c) cerebellar volumes will be preserved in the WS group (no a priori expectations regarding absolute or relative preservation); and (d) such regional volume preservation may be due to a more balanced ratio of cortical to white matter (i.e., a lesser reduction in white matter in the cerebellum than what is observed in the cerebrum).

\section{Materials and methods}

\subsection{Participants}

Participants were distributed in two groups: a group of 17 individuals with WS ( 10 females; aged $11-32 ; M, S D=19.24$, 6.04 years) and a control group of 15 individuals ( 8 females; aged $11-28 ; M, S D=19.20,5.55$ years). Participants in the WS group tested positive in fluorescence in situ hybridization (FISH) for deletion of the elastin gene in chromosome 7 (Ewart et al., 1993), and the presence of any sensorial or speech disorder, as well as comorbidity with severe psychopathology not associated with the syndrome were defined as exclusion criteria. The control group was composed of typically developing individuals without a history of sensorial, psychiatric, or neurological disorder or cognitive impairment. Table 1 displays the main socio-demographic characteristics of the sample. The groups did not differ significantly in terms of age, $t(30)=0.02$, 
Table 1

Socio-demographic characteristics.

\begin{tabular}{|c|c|c|c|c|}
\hline & \multicolumn{2}{|c|}{ WS $(n=17)$} & \multicolumn{2}{|c|}{ TD $(n=15)$} \\
\hline & $\overline{M(S D)}$ & Range & $\overline{M(S D)}$ & Range \\
\hline \multirow[t]{2}{*}{$\overline{\text { Age }}$} & $19.24(6.04)$ & $\overline{11-32}$ & $19.20(5.55)$ & $\overline{11-28}$ \\
\hline & $M d n$ & Range & $M d n$ & Range \\
\hline \multirow[t]{2}{*}{ SES } & 3 & $1-5$ & 3 & $1-4$ \\
\hline & $n$ & $\%$ & $n$ & $\%$ \\
\hline \multicolumn{5}{|l|}{ Sex } \\
\hline Male & 7 & 41.2 & 7 & 46.7 \\
\hline Female & 10 & 58.8 & 8 & 53.3 \\
\hline
\end{tabular}

Note. SES-social economic index (Graffar).

$p=.986$ or social-economic status, $U=116.50, p=0.682$, although there was a significant difference in IQ $t(29)=-17.15$, $p<0.001$ (IQ was not available for one participant with WS).

\subsection{Data acquisition and analysis}

Participants were scanned on a clinical approved 1.5 T General Electric Healthcare MRI on Hospital Santo António, Porto. A T1 whole brain high-resolution anatomical sequence, Spoiled gradient Echo (SPGR), was performed with the following imaging parameters: repetition time $(T R)=3.5 \mathrm{~s}$, echo time $(\mathrm{TE})=5 \mathrm{~ms}, 124$ coronal slices with no gap, field-of view $($ FoV $)=276 \times 192$ matrix, flip angle $(F A)=45^{\circ}$, in-plane resolution $=1.25 \times 1.25 \mathrm{~mm}^{2}$ and slice thickness $=1.5 \mathrm{~mm}$.

Before any data processing or analysis, the acquisitions were examined and then confirmed that they were not affected by critical head motion and participants had no brain lesions.

Segmentation and labeling of brain structures based on T1 SPGR acquisition, were performed using the freely available Freesurfer toolkit version 5.0 (http://surfer.nmr.mgh.harvard.edu). The Freesurfer pipeline uses a probabilistic brain atlas estimated from a manual labeled training set proposed in 2002 (Fischl et al., 2002) and has undergone several improvements over the years (Fischl et al., 2004; Han \& Fischl, 2007). The technique has been shown to be comparable in accuracy to manual labeling and reliable and robust across sessions, scanner platforms, updates and field strengths (Han \& Fischl, 2007; Jovicich et al., 2009). Some studies have also shown the robust and accurate segmentation results on cerebellar analysis (Hwang, Kim, Han, \& Park, 2011; Weier et al., 2012).

The general workflow of Freesurfer consists of: conversion of DICOM format to the Freesurfer standard format; data processed by a 30-step procedure including pre-processing of MRI images, non-parametric, and non-uniform intensity normalization; normalization to the standard Talairach space; intensity normalization with corrections of fluctuations in scan intensity; skull strip; registration using a transform matrix to align the patient volume with the Freesurfer atlas when applying segmentation labels; reconstruction of cortical and pial surfaces with a sub millimeter precision; inflation of each tessellated cortical surface representing gray-white matter boundary to normalize the individual differences in the depth of gyri-sulci. This generated intracranial volume (ICV), gray and white matter volumes for cerebellum and cerebrum. After visual inspection, manual adjustments were needed in the normalization procedure, skull strip, segmentations and pial surface boundary. Trained researchers controlled the quality and accuracy of the reconstructions, and visually inspected the quality of brain segmentations/labels. Estimated intracranial volume validated by Buckner and colleagues (Buckner et al., 2004) was used to correct the volumetric data.

\subsection{Data analysis}

Statistical calculations were performed using PASW Statistics 19 (IBM SPSS Statistics). Assumptions of normality were met (non significant Kolmogorov-Smirnov and Shapiro-Wilk tests). T-tests were conducted to test for differences in cerebrum volumes between individuals with WS and controls. Two-way mixed analyses of variance were used to determine cerebellum volume differences between both groups. Thus, group (WS vs. controls) was used as the between-subject factor and hemisphere (left vs. right) as the within-subject factor. If a main effect for group was found, $t$-tests were used to test the mean difference. Effect sizes were also calculated for group differences using Cohen's $d$. A $p$ value less than 0.05 was assumed to denote a significant difference.

\section{Results}

ICVs were significantly reduced in WS (16.4\%), when compared to controls, $t(30)=-5.63, p<0.001 ; d=-2.06$. In fact, absolute volumes of gray matter, $t(30)=-2.63, p<0.05 ; d=0.96$, white matter, $t(30)=-6.02, p<0.001 ; d=-2.20$, and cerebrospinal fluid, $t(30)=-2.57, p<0.05 ; d=-0.94$, were significantly reduced in the clinical group. When relative volumes were computed (in proportion to ICV), white matter volumes were significantly decreased in WS, $t(30)=-3.55$, $p<0.001 ; d=-1.30$, but gray matter, $t(30)=-1.79, p=0.084 ; d=-0.65$, and cerebrospinal fluid volumes, $t(30)=-0.12$, $p=.909 ; d=-0.04$, were relatively preserved (Table 2 ). 
Table 2

Cerebrum and cerebellum volumes.

\begin{tabular}{|c|c|c|}
\hline \multirow[t]{2}{*}{ Region } & WS & TD \\
\hline & $M(S D)$ & $M(S D)$ \\
\hline \multicolumn{3}{|l|}{ Raw volume $\left(\mathrm{cm}^{3}\right)$} \\
\hline ICV & $1269.13(115.41)$ & $1516.42(133.02)$ \\
\hline Cerebral white matter & $346.48(36.94)$ & $456.00(63.92)$ \\
\hline Cerebral gray matter & $535.17(64.10)$ & 600.77 (76.95) \\
\hline Cerebrospinal fluid & $93.58(19.52)$ & $112.17(21.34)$ \\
\hline Whole cerebellum & 138.47 (14.99) & $154.30(13.56)$ \\
\hline Cerebellar white matter & $25.59(3.03)$ & $30.04(3.85)$ \\
\hline Cerebellar cortex & 112.87 (13.19) & $124.26(11.28)$ \\
\hline \multicolumn{3}{|l|}{ Ratio to ICV (\%) } \\
\hline Cerebellar volume & $10.91(0.67)$ & $10.20(0.76)$ \\
\hline \multicolumn{3}{|c|}{ Ratio to whole cerebellum volume (\%) } \\
\hline Cerebellar white matter & $18.5(1.7)$ & $19.5(1.8)$ \\
\hline Cerebellar cortex & $76.7(19.8)$ & $80.5(1.2)$ \\
\hline
\end{tabular}

\subsection{Absolute cerebellum volumes}

Two-way mixed analyses of variance of absolute cerebellum volumes revealed a significant group effect (WS vs. TD), $F(1,30)=9.72, p=0.004$, as well as a side (left vs. right) effect, $F(1,30)=17.21, p<0.001$, but no interaction effect $F(1,30)=1.60, p=0.216$. When analyzing cerebellum white matter volumes we found a significant group effect, $F(1,30)=13.34, p=0.001$, as well as a side effect, $F(1,30)=10.45, p=0.003$, but no interaction effect, $F(1,30)=2.65$, $p=0.114$. Finally, the analysis of cortical volumes revealed a significant group effect, $F(1,30)=6.79, p=0.014$, as well as a side effect, $F(1,30)=40.31, p<0.001$, but no interaction effect, $F(1,30)=0.60, p=0.445$.

Follow-up $t$-tests showed that whole cerebellum volumes were significantly reduced among individuals with WS (by $10.3 \%), t(30)=-3.12, p<0.01 ; d=-1.14$, as were absolute cerebellum white matter, $t(30)=-3.65, p<0.001 ; d=-1.33$, and cortex volumes, $t(30)=-2.61, p<0.05 ; d=-0.95$. Regarding the side effect, right cerebellum volumes were significantly larger than left volumes, $t(31)=-4.08, p<0.001 ; d=-0.20$. The same trend was observed for cerebellum cortex volumes, $t(31)=-6.35, p<0.001 ; d=-0.31$. Left cerebellum white matter volumes were larger than right volumes, $t(31)=3.26$, $p<0.01 ; d=0.24$.

\subsection{Relative cerebellum volumes}

A two-way mixed analysis of variance of cerebellum volume (relative to ICV) revealed a significant group effect (WS vs. TD), $F(1,30)=8.04, p=0.008$, as well as a side (left vs. right) effect, $F(1,30)=15.51, p<0.001$, but no interaction effect $F(1,30)=0.85, p=0.363$. When analyzing cerebellum white matter volumes (relative to whole cerebellum) we found a significant side effect, $F(1,30)=44.12, p<0.001$, but no significant group effect, $F(1,30)=2.27, p=0.142$, or interaction effect, $F(1,30)=2.62, p=0.116$. Finally, the analysis of cerebellum gray matter volumes (relative to whole cerebellum) revealed a significant side effect, $F(1,30)=44.12, p<0.001$, but no significant group effect, $F(1,30)=2.27, p=0.142$, or interaction effect, $F(1,30)=2.62, p=0.116$.

Follow-up t-tests evidenced that cerebellum volumes (relative to ICV) were significantly larger in the clinical group (by $7 \%), t(30)=2.84, p<0.01 ; d=1.04$. Furthermore, relative cerebellum white matter, $t(30)=-3.18, p<0.01 ; d=-1.16$, and cortex volumes (both relative to whole cerebellum), $t(30)=-3.18, p<0.01 ; d=-1.16$, did not significantly differ between the groups. Regarding the side effect, right relative cerebellum volumes were significantly larger than left volumes, $t(31)=-3.90, p<0.001 ; d=-0.30$. The same trend was observed for relative cerebellum cortex volumes, $t(31)=-6.59$, $p<0.001 ; d=-0.61$. Relative cerebellum white matter volumes were larger in the left (vs. right) hemisphere, $t(31)=6.59$, $p<0.001 ; d=0.61$.

\section{Discussion}

We confirmed previous findings of an overall cerebral volume reduction in our cohort of patients with WS (Menghini et al., 2011; Reiss et al., 2000; Sampaio et al., 2008). In fact, cerebrum volumes were $16.4 \%$ smaller in the clinical group than in the typically developing comparison group. Significant reductions were also observed for absolute volumes of cerebral white matter, gray matter and cerebrospinal fluid, but it should be noted that reductions in white matter reached an effect size more than twice the ones observed for the remaining measures. In line with this result, and also in accordance with a previous report by Reiss et al. (2000), individuals with WS showed a disproportionate reduction in cerebral white matter (relative to ICV), but not gray matter or cerebrospinal fluid. Taken together, such evidence suggests that the decrease observed in overall cerebral size may be mostly accounted for by uneven reductions in white matter. In typical development, white matter volume has been shown to increase linearly with age (Barnea-Goraly et al., 2004; Matsuzawa et al., 2001), and 
denser and more organized white matter circuitry has been associated with better cognitive performance in individuals with normal or impaired cognitive ability (Schmithorst, Wilke, Dardzinski, \& Holland, 2005; Yu et al., 2008). Therefore, the observed volumetric changes in white matter are very likely implicated in the atypical developmental trajectories exhibited by patients with WS, particularly in what concerns cognition.

Absolute cerebellar volumes were reduced in the WS group, but to a lesser extent than what was observed for cerebral volumes - about $10 \%$ (vs. $16.4 \%$ seen in the cerebrum) - thus replicating previous results by Reiss et al. (2000). Furthermore, we also observed significant reductions in absolute cerebellar white matter and cortex volumes. In contrast, cerebellar volumes (relative to ICV) were significantly larger in the clinical group. Previous work using distinct methodological approaches reported similar trends (Jones et al., 2002; Reiss et al., 2000). Using a qualitative approach, Jones et al. (2002) reported that raters (experienced neuroradiologists blind to the research hypotheses and to participant status) noted abnormal cerebellar enlargement as a defining feature of MRI scans of children with WS (versus the comparison groups). Moreover, using a semi automated MRI analysis, Reiss et al. (2000) found that cerebellar volume (in proportion to cerebral volume) was increased in a sample of adults with WS. In addition, and in accordance with the latter authors, we found that relative volumes of cerebellar white matter and cerebellar cortex were indistinguishable between the groups.

Taken together, our results show that even though individuals with WS had significantly smaller cerebrums (and cerebellums), cerebellar volumes relative to ICV were significantly enlarged. In addition, while gray matter was relatively spared and white matter disproportionately reduced in the cerebrum in WS, relative cerebellar cortex and white matter volumes were preserved, offering support to the thus far unreplicated results by Reiss et al. (2000). Therefore, the observed increase in relative cerebellar volume in the clinical group may be due to a more balanced ratio of cortical matter to white matter (i.e., a lesser reduction in white matter in the cerebellum than what is observed in the cerebrum).

The alterations in cerebellar volume reported in the present work suggest that volumetric changes in this region may account (at least partially) for the cognitive, affective, and motor profile typically shown by individuals with WS. There is some recent evidence supporting cerebellar alterations as relevant neuroanatomical correlates of the cognitive deficits associated with WS. For instance, Campbell et al. (2009) found that ratings of inattention were associated with volumetric increases in the cerebellum, while Menghini et al. (2011) found that cerebellar gray matter density was positively related to performance on linguistic and visual-spatial measures. To our knowledge, no similar correlational evidence has been reported for affective or motor alterations in this disorder.

The aforementioned differential brain tissue patterns are likely associated with the abnormal brain development in WS. It is noteworthy that several genes essential to neuronal migration and maturation are deleted in WS, such as LIMK1, CYLN2 (Marenco et al., 2007); FZD3 (Wang \& Bellugi, 1994) and FZD9 (Zhao et al., 2005). Indeed, one study using diffusion tensor imaging (DTI) found extensive disruptions in white matter tracts in a sample of high-functioning adults with WS, thus providing supporting evidence for atypical patterns of neuronal migration in the later prenatal stages (Marenco et al., 2007). Furthermore, brain development processes like synaptic pruning and myelination occur concomitantly in the typically developing brain, originating gray matter decreases as well as white matter increases in adolescence and adulthood (Giedd et al., 1999; Sowell, Thompson, \& Toga, 2004). Our results therefore support that these brain processes are likely altered in WS.

\section{Conclusion}

We found that while absolute cerebellar volumes were reduced in WS, cerebellar volumes relative to ICV were significantly enlarged in the clinical group, comparing to the typically developing group. In addition, gray matter was relatively spared and white matter disproportionately reduced in the cerebrum in WS, but cerebellar cortex and white matter volumes were relatively preserved. These findings lend support to the hypothesis that volume alterations in the cerebellum may be associated with the cognitive, affective and motor profiles in WS. Future studies are needed to explore the associations between behavioral measures of these profiles and cerebellar structural and functional anomalies in WS.

\section{Acknowledgments}

This research was supported by FEDER funds through the Competitive Factors Operational Programme-COMPETE, by national funds from the Portuguese Foundation for Science and Technology (grant PTDC/PSI-PCL/115316/2009).

\section{References}

Atkinson, J., Braddick, O., Anker, S., Curran, W., Andrew, R., Wattam-Bell, J., \& Braddick, F. (2003). Neurobiological models of visuospatial cognition in children with Williams syndrome: Measures of dorsal-stream and frontal function. Developmental Neuropsychology, 23(1-2), 139-172.

Barnea-Goraly, N., Kwon, H., Menon, V., Eliez, S., Lotspeich, L., \& Reiss, A. L. (2004). White matter structure in autism: Preliminary evidence from diffusion tensor imaging. Biological Psychiatry, 55(3), 323-326.

Bellugi, U., Korenberg, J. R., \& Klima, E. S. (2001). Williams syndrome: An exploration of neurocognitive and genetic features. Clinical Neuroscience Research, 1(3), $217-229$.

Brock, J. (2007). Language abilities in Williams syndrome: A critical review. Development and Psychopathology, 19(01), 97-127.

Buckner, R. L., Head, D., Parker, J., Fotenos, A. F., Marcus, D., Morris, J. C., \& Snyder, A. Z. (2004). A unified approach for morphometric and functional data analysis in young, old, and demented adults using automated atlas-based head size normalization: Reliability and validation against manual measurement of total 
intracranial volume. NeuroImage, 23(2), 724-738. http://dx.doi.org/10.1016/j.neuroimage.2004.06.018. [Research Support, Non-U.S. Gov't. Research Support, U.S. Gov't, P.H.S.]

Campbell, L. E., Daly, E., Toal, F., Stevens, A., Azuma, R., Karmiloff-Smith, A., \& Murphy, K. C. (2009). Brain structural differences associated with the behavioural phenotype in children with Williams syndrome. Brain Research, 1258, 96-107.

Capitão, L., Sampaio, A., Férnandez, M., Sousa, N., Pinheiro, A., \& Gonçalves, O. F. (2011). Williams syndrome hypersociability: A neuropsychological study of the amygdala and prefrontal cortex hypotheses. Research in Developmental Disabilities, 32, 1169-1179.

Chapman, C. A., du Plessis, A., \& Pober, B. R. (1996). Neurologic findings in children and adults with Williams syndrome. Journal of Child Neurology, 11(1), 63-65.

Chiang, M.-C., Reiss, A. L., Lee, A. D., Bellugi, U., Galaburda, A. M., Korenberg, J. R., \& Thompson, P. M. (2007). 3D pattern of brain abnormalities in Williams syndrome visualized using tensor-based morphometry. Neuroimage, 36(4), 1096.

Desmond, J. E., Gabrieli, J. D., \& Glover, G. H. (1998). Dissociation of frontal and cerebellar activity in a cognitive task: Evidence for a distinction between selection and search. Neuroimage, 7(4), 368-376.

Dykens, E. M. (2003). Anxiety, fears, and phobias in persons with Williams syndrome. Developmental Neuropsychology, 23(1-2), 291-316.

Ewart, A. K., Morris, C. A., Atkinson, D., Jin, W., Sternes, K., Spallone, P., \& Keating, M. T. (1993). Hemizygosity at the elastin locus in a developmental disorder, Williams syndrome. Nature Genetics, 5(1), 11-16. http://dx.doi.org/10.1038/ng0993-11

Fink, G. R., Marshall, J. C., Shah, N. J., Weiss, P. H., Halligan, P. W., Grosse-Ruyken, M., \& Freund, H.-J. (2000). Line bisection judgments implicate right parietal cortex and cerebellum as assessed by fMRI. Neurology, 54(6), 1324-1331.

Fischl, B., Salat, D. H., Busa, E., Albert, M., Dieterich, M., Haselgrove, C., \& Klaveness, S. (2002). Whole brain segmentation: Automated labeling of neuroanatomical structures in the human brain. Neuron, 33(3), 341-355.

Fischl, B., Salat, D. H., van der Kouwe, A. J., Makris, N., Ségonne, F., Quinn, B. T., \& Dale, A. M. (2004). Sequence-independent segmentation of magnetic resonance images. Neuroimage, 23, S69-S84.

Giedd, J. N., Blumenthal, J., Jeffries, N. O., Castellanos, F. X., Liu, H., Zijdenbos, A., \& Rapoport, J. (1999). Brain development during childhood and adolescence: A longitudinal MRI study. Nature Neuroscience, 2, 861-863.

Gonçalves, O. F., Pinheiro, A., Sampaio, A., Sousa, N., Férnandez, M., \& Henriques, M. (2010). The narrative profile in Williams syndrome: There is more to storytelling than just telling a story. British Journal of Development Disabilities, 56(111), 89-109.

Grodd, W., Hülsmann, E., Lotze, M., Wildgruber, D., \& Erb, M. (2001). Sensorimotor mapping of the human cerebellum: fMRI evidence of somatotopic organization. Human Brain Mapping, 13(2), 55-73.

Han, X., \& Fischl, B. (2007). Atlas renormalization for improved brain MR image segmentation across scanner platforms. IEEE Transactions on Medical Imaging, 26, $479-486$.

Harrington, D. L., Boyd, L. A., Mayer, A. R., Sheltraw, D. M., Lee, R. R., Huang, M., \& Rao, S. M. (2004). Neural representation of interval encoding and decision making. Cognitive Brain Research, 21(2), 193-205.

Hofer, A., Siedentopf, C. M., Ischebeck, A., Rettenbacher, M. A., Verius, M., Felber, S., \& Wolfgang Fleischhacker, W. (2007). Sex differences in brain activation patterns during processing of positively and negatively valenced emotional words. Psychological Medicine, 37(1), 109-120.

Howlin, P., Davies, M., \& Udwin, O. (1998). Cognitive functioning in adults with Williams syndrome. Journal of Child Psychology and Psychiatry, 39(2), 183-189.

Hwang, J., Kim, J., Han, Y., \& Park, H. (2011). An automatic cerebellum extraction method in T1-weighted brain MR images using an active contour model with a shape prior. Magnetic Resonance Imaging, 29(7), 1014-1022.

Jernigan, T. L., Bellugi, U., Sowell, E., Doherty, S., \& Hesselink, J. R. (1993). Cerebral morphologic distinctions between Williams and Down syndromes. Archives of Neurology, 50(2), 186.

Jones, W., Bellugi, U., Lai, Z., Chiles, M., Reilly, J., Lincoln, A., \& Adolphs, R. (2000). II. Hypersociability in Williams syndrome. Journal of Cognitive Neuroscience, 12(Suppl 1), 30-46.

Jones, W., Hesselink, J., Duncan, T., Matsuda, K., \& Bellugi, U. (2002). Cerebellar abnormalities in infants and toddlers with Williams syndrome. Developmental Medicine E Child Neurology, 44(10), 688-694.

Jovicich, J., Czanner, S., Han, X., Salat, D., van der Kouwe, A., Quinn, B., \& Blacker, D. (2009). MRI-derived measurements of human subcortical, ventricular and intracranial brain volumes: Reliability effects of scan sessions, acquisition sequences, data analyses, scanner upgrade, scanner vendors and field strengths. Neuroimage, 46(1), 177-192.

Karmiloff-Smith, A., Brown, J. H., Grice, S., \& Paterson, S. (2003). Dethroning the myth: Cognitive dissociations and innate modularity in Williams syndrome. Developmental Neuropsychology, 23(1-2), 227-242.

Korenberg, J. R., Chen, X. N., Hirota, H., Lai, Z., Bellugi, U., Burian, D., \& Matsuoka, R. (2000). VI. Genome structure and cognitive map of Williams syndrome. Journal of Cognitive Neuroscience, 12(Supplement 1), 89-107.

Leyfer, O. T., Woodruff-Borden, J., Klein-Tasman, B. P., Fricke, J. S., \& Mervis, C. B. (2006). Prevalence of psychiatric disorders in 4 to 16 -year-olds with Williams syndrome. American Journal of Medical Genetics Part B: Neuropsychiatric Genetics, 141(6), 615-622.

Makris, N., Schlerf, J. E., Hodge, S. M., Haselgrove, C., Albaugh, M. D., Seidman, L. J., \& Caviness, V. S., Jr. (2005). MRI-based surface-assisted parcellation of human cerebellar cortex: An anatomically specified method with estimate of reliability. Neuroimage, 25(4), 1146-1160.

Marenco, S., Siuta, M. A., Kippenhan, J. S., Grodofsky, S., Chang, W., Kohn, P., \& Meyer-Lindenberg, A. (2007). Genetic contributions to white matter architecture revealed by diffusion tensor imaging in Williams syndrome. Proceedings of the National Academy of Sciences of the United States of America, 104(38), 1511715122.

Matsuzawa, J., Matsui, M., Konishi, T., Noguchi, K., Gur, R. C., Bilker, W., \& Miyawaki, T. (2001). Age-related volumetric changes of brain gray and white matter in healthy infants and children. Cerebral Cortex, 11(4), 335-342.

Menghini, D., Di Paola, M., Federico, F., Vicari, S., Petrosini, L., Caltagirone, C., \& Bozzali, M. (2011). Relationship between brain abnormalities and cognitive profile in Williams syndrome. Behavior Genetics, 41(3), 394-402.

Nitschke, M. F., Kleinschmidt, A., Wessel, K., \& Frahm, J. (1996). Somatotopic motor representation in the human anterior cerebellum A high-resolution functional MRI study. Brain, 119(3), 1023-1029.

Oscarsson, O. (1965). Functional organization of the spino-and cuneocerebellar tracts. Physiological Reviews, 45(3), 495-522.

Osório, A., Cruz, R., Sampaio, A., Garayzábal, E., Martínez-Regueiro, R., Gonçalves, O. F., \& Fernández-Prieto, M. (2012). How executive functions are related to intelligence in Williams syndrome. Research in Developmental Disabilities, 33(4), 1169-1175.

Porter, M. A., Coltheart, M., \& Langdon, R. (2007). The neuropsychological basis of hypersociability in Williams and Down syndrome. Neuropsychologia, 45(12), 2839-2849.

Reiss, A. L., Eliez, S., Schmitt, J. E., Straus, E., Lai, Z., Jones, W., \& Bellugi, U. (2000). IV. Neuroanatomy of Williams syndrome: A high-resolution MRI study. Journal of Cognitive Neuroscience, 12(Suppl 1), 65-73.

Rhodes, S. M., Riby, D. M., Park, J., Fraser, E., \& Campbell, L. E. (2010). Executive neuropsychological functioning in individuals with Williams syndrome. Neuropsychologia, 48(5), 1216-1226.

Sampaio, A., Férnandez, M., Henriques, M., Carracedo, A., Sousa, N., \& Gonçalves, O. F. (2009). Cognitive functioning in Williams syndrome: A study in Portuguese and Spanish patients. European Journal of Paediatric Neurology, 13(4), 337-342.

Sampaio, A., Sousa, N., Férnandez, M., Vasconcelos, C., Shenton, M. E., \& Gonçalves, O. F. (2008). MRI assessment of superior temporal gyrus in Williams syndrome. Cognitive and Behavioral Neurology, 21(3), 150,. Official Journal of the Society for Behavioral and Cognitive Neurology.

Schmahmann, J. D. (2001). The cerebrocerebellar system: Anatomic substrates of the cerebellar contribution to cognition and emotion. International Review of Psychiatry, 13(4), 247-260.

Schmahmann, J. D. (2004). Disorders of the cerebellum: Ataxia, dysmetria of thought, and the cerebellar cognitive affective syndrome. Journal of Neuropsychiatry and Clinical Neurosciences, 16(3), 367-378.

Schmahmann, J. D., MacMore, J., \& Vangel, M. (2009). Cerebellar stroke without motor deficit: Clinical evidence for motor and non-motor domains within the human cerebellum. Neuroscience, 162(3), 852. 
Schmahmann, J. D., \& Sherman, J. C. (1998). The cerebellar cognitive affective syndrome. Brain, 121(4), 561-579.

Schmithorst, V.J., Wilke, M., Dardzinski, B. J., \& Holland, S. K. (2005). Cognitive functions correlate with white matter architecture in a normal pediatric population: A diffusion tensor MRI study. Human Brain Mapping, 26(2), 139-147.

Schmitt, J. E., Eliez, S., Bellugi, U., \& Reiss, A. L. (2001). Analysis of cerebral shape in Williams syndrome. Archives of Neurology, $58(2), 283$.

Sowell, E. R., Thompson, P. M., \& Toga, A. W. (2004). Mapping changes in the human cortex throughout the span of life. Neuroscientist, 10(4), $372-392$.

Stoodley, C. J., \& Schmahmann, J. D. (2010). Evidence for topographic organization in the cerebellum of motor control versus cognitive and affective processing. Cortex, 46(7), 831-844.

Strømme, P., Bjømstad, P. G., \& Ramstad, K. (2002). Prevalence estimation of Williams syndrome. Journal of Child Neurology, 17(4), 269.

Trauner, D. A., Bellugi, U., \& Chase, C. (1989). Neurologic features of Williams and Down syndromes. Pediatric Neurology, 5(3), $166-168$.

Udwin, O. (2002). Williams and Smith-Magenis syndromes. In P. Howlin \& O. Udwin (Eds.), Outcomes in neurodevelopmental and genetic disorders (pp. 299-324). New York, NY: Cambridge University Press.

Valera, E. M., Faraone, S. V., Biederman, J., Poldrack, R. A., \& Seidman, L. J. (2005). Functional neuroanatomy of working memory in adults with attention-deficit/ hyperactivity disorder. Biological Psychiatry, 57(5), 439-447.

Vingerhoets, G., De Lange, F. P., Vandemaele, P., Deblaere, K., \& Achten, E. (2002). Motor imagery in mental rotation: An fMRI study. Neuroimage, 17(3), 1623-1633.

Wang, P. P., \& Bellugi, U. (1994). Evidence from two genetic syndromes for a dissociation between verbal and visual-spatial short-term memory. Journal of Clinical and Experimental Neuropsychology, 16(2), 317-322.

Weier, K., Beck, A., Magon, S., Amann, M., Naegelin, Y., Penner, I. K., \& Radue, E.-W. (2012). Evaluation of a new approach for semi-automatic segmentation of the cerebellum in patients with multiple sclerosis. Journal of Neurology, 259(12), 2673-2680.

Xiang, H., Lin, C., Ma, X., Zhang, Z., Bower, J. M., Weng, X., \& Gao, J. H. (2003). Involvement of the cerebellum in semantic discrimination: An fMRI study. Human Brain Mapping, 18(3), 208-214.

Yu, C., Li, J., Liu, Y., Qin, W., Li, Y., Shu, N., \& Li, K. (2008). White matter tract integrity and intelligence in patients with mental retardation and healthy adults. Neuroimage, 40(4), 1533-1541.

Zhao, C., Avilés, C., Abel, R. A., Almli, C. R., McQuillen, P., \& Pleasure, S. J. (2005). Hippocampal and visuospatial learning defects in mice with a deletion of frizzled 9 , a gene in the Williams syndrome deletion interval. Development, 132(12), 2917-2927. 